\title{
Erratum to: History of Maltreatment in Childhood and Subsequent Parenting Stress in At-Risk, First-Time Mothers: Identifying Points of Intervention During Home Visiting
}

\author{
Chad E. Shenk ${ }^{1,2} \cdot$ Robert T. Ammerman ${ }^{3}$ - Angelique R. Teeters ${ }^{3}$. \\ Heather E. Bensman ${ }^{3}$ - Elizabeth K. Allen ${ }^{1}$. Frank W. Putnam ${ }^{4}$ • Judith B. Van Ginkel ${ }^{3}$
}

Published online: 8 March 2017

(C) Society for Prevention Research 2017

Erratum to: Prev Sci (2017)

DOI 10.1007/s11121-017-0758-4

As a result of a typesetting error, the above referenced article was published with an incorrectly placed arrow in Figure 2. The corrected Figure 2 demonstrates the cross-lagged nature of the mediation model tested.

The original article has been corrected.

The online version of the original article can be found at http://dx.doi.org/ 10.1007/s11121-017-0758-4.

Chad E. Shenk

ces140@psu.edu

1 Department of Human Development and Family Studies, The Pennsylvania State University, 115 Health and Human Development Building, University Park, PA 16802, USA

2 Department of Pediatrics, College of Medicine, The Pennsylvania State University, State College, PA, USA

3 Department of Pediatrics, College of Medicine, Cincinnati Children's, Hospital Medical Center and University of Cincinnati, Cincinnati, OH, USA

4 Department of Psychiatry, School of Medicine, University of North Carolina, Chapel Hill, NC, USA 